JIME (Journal of Industrial and Manufacture Engineering), 5(2) November 2021

ISSN 2549-6328 (Print) ISSN2549-6336 (Online) DOI : 10.31289/jime.v5i2.5163

JIME

(Journal of Industrial and Manufacture Engineering)

Available online http://ojs.uma.ac.id/index.php/jime

\title{
Analisa Teknis dan Ekonomis pada Desain Alat Decanter pada Pabrik Biodiesel
}

\section{Technical and Economic Analysis on Equipment Design of Decanter in Biodiesel Industry}

\author{
Erwan Adi Saputro*1), AR Yelvia Sunarti2), Tahan Aprijal Simamora ${ }^{3)}$, dan Achmad Rizaldi ${ }^{4}$ \\ Program Studi Teknik Kimia, Fakultas Teknik. Universitas Pembangunan Nasional.
}

Diterima: Maret 2021; Disetujui: November 2021; Dipublikasi: November 2021;

*Coresponding author : erwanadi.tk@upnjatim.ac.id

\begin{abstract}
Abstrak
Pemerintah Indonesia menetapkan kebijakan energi nasional dalam pengembangan sumber energi alternatif sebagai pengganti BBM, salah satunya biodiesel. Saat ini, pengembangan biodiesel umumnya menggunakan kapasitas relatif kecil dengan proses batch. Beberapa peralatan pendukung pada proses batch produksi biodiesel yaitu alat produksi biodiesel dan alat pemisahan produk biodiesel. Pemisahan produk biodiesel dilakukan untuk mendapatkan kemurnian produk. Salah satu alat yang digunakan dalam pemisahan produk biodiesel adalah decanter. Decanter merupakan komponen peralatan pada pabrik pengolahan kelapa sawit maupun biodiesel, yang berfungsi untuk memisahkan minyak dengan senyawa lain seperti gliserin, berdasarkan atas perbedaan densitas, sebelum menuju ke tahap pemurnian seperti kolom distilasi. Penelitian ini bertujuan untuk memprediksi harga decanter di masa mendatang berdasarkan spesifikasi alat. Penelitian ini dilakukan dengan menentukan spesifikasi alat yang diperlukan berdasarkan kapasitas dan menghitung penentuan harga menggunakan persamaan Peters \& Timmerhauss dan dibandingkan dengan harga di pasaran saat ini. Hasil perhitungan menunjukkan bahwa semakin besar kapasitas maka semakin besar dimensi alat decanter seperti volume, panjang, diameter tangki, tebal shell yang diperlukan. Selain itu, apabila semakin besar kapasitas dan diameter yang diperlukan maka harganya semakin mahal. Berdasarkan perhitungan penentuan harga decanter hasilnya sesuai dengan harga yang ada dipasaran saat ini. Sehingga metode perhitungan ini layak digunakan untuk memprediksi harga decanter.
\end{abstract}

Kata Kunci : Spesifikasi; Harga; Alat; Decanter; Biodisel

\begin{abstract}
The Indonesian Government has established a national energy policy for the development of alternative energy sources as a substitute for fuel, one of which is biodiesel. Currently, the development of biodiesel uses a relatively small capacity (batch process). Supporting equipment for the biodiesel production batch process are biodiesel production equipment and biodiesel product separation equipment. Separation of biodiesel to obtain product purity. One of the equipment components in the separation of biodiesel is a decanter. The decanter is a component of equipment in palm oil and biodiesel plants, to separate oil from other compounds such as glycerin, based on differences density, before the purification process (distillation column). This study aims to predict future decanter prices based on equipment specifications. This research determines the required equipment specifications based on capacity and calculates the pricing using the Peters \& Timmerhauss equation and compares prices in the current market. Calculations show that the increase the capacity will increase the dimensions of the decanter (volume, length, tank diameter, and shell thickness). Increasing capacity and diameter will be more expensive. Based on the calculation of the determination of decanter prices, the calculation is according to the current market price. So that this calculation method is feasible to use to predict the price of a decanter.
\end{abstract}

Keywords: Specification, Price, Equipment, Decanter, Biodiesel

How to Cite: Saputro, Erwan Adi, AR Yelvia dkk (2021). Analisa Teknis dan Ekonomis pada Desain Alat Decanter pada Pabrik Biodiesel. JIME (Journal of Industrial and Manufacture Engineering). 5(2): 130 - 136 



\section{PENDAHULUAN}

Kebijakan Energi Nasional untuk mengembangkan sumber energi alternatif sebagai pengganti Bahan Bakar Minyak telah berjalan dengan pengembangan Bahan Bakar Nabati (biofuel), salah satunya biodiesel.

Potensi pengembangan biodiesel Indonesia cukup besar karena disamping sebagai penghasil CPO terbesar di dunia, Indonesia juga memiliki banyak spesies tanaman yang minyaknya dapat digunakan sebagai bahan baku biodiesel (Soerawidjaja, dkk., 2005).

Proses pembuatan biodiesel sejauh ini menggunakan kapasitas yang relatif kecil proses yang dipilh yaitu proses batch, cara yang dipakai saat proses pemisahan biodiesel, gliserin dan kotoran-kotoran lain menggunakan proses pengendapan (settling). Pengendapan memerlukan tempat dan dimensi yang besar serta membutuhkan waktu yang relatif lama dan sulit terus-menerus (continyu). Salah satu cara yang digunakan untuk pemisahan biodiesel dari campurannya adalah dengan memanfatkan gaya sentrifugal (Budiman, 2009).

Decanter yaitu alat untuk memisahkan liquid-liquid dengan prinsip perbedaan densitas dan kelarutan yang rendah (Gambar 1). Penggunaan proses pemisahan dengan alat decanter yaitu agar proses dapat berjalan dengan temperatur yang rendah, karena pada temperatur yang tinggi densitas akan semakin kecil dan kelarutannya akan semakin tinggi, sehingga campuran sulit dipisahkan (Palm Oil Industrial Engineering, 2013).

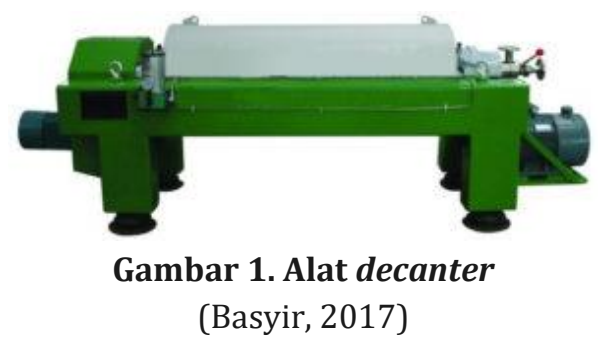

Pada penelitian zhu et al., (2020) telah melakukan pemodelan CFD untuk sentrifuge decanter tiga fase yang biasanya digunakan dalam industri minyak untuk pemisahan air/minyak/pasir.

Di dalam mendesain pabrik biodiesel perlu adanya perencanaan termasuk prediksi harga alat alat industri. Tujuan penelitian ini adalah untuk memprediksi harga alat decanter dan membandingkannya dengan harga pasar.

\section{METODE PENELITIAN}

Metode yang digunakan dalam penelitian ini adalah study literatur dan perhitungan analisis. Untuk menjaga keakuratan data maka langkah langkah perhitungan dilakukan dalam beberapa tahapan, yaitu perhitungan spesifikasi alat dan perhitungan harga alat.

Langkah-langkah menghitung spesifikasi alat Decanter adalah sebagai berikut:

a. Rate massa bahan masuk ke Decanter (ton/tahun) dan (kg/jam)

b. Menghitung densitas campuran bahan yang masuk ke Decanter

$$
\frac{1}{\rho}=\sum \frac{x i}{\rho} \quad \rho=\frac{1}{\sum \frac{x i}{\rho}}
$$

Keterangan:

$\rho \quad$ : densitas $(\mathrm{gr} / \mathrm{cc})$

$\mathrm{xi} \quad$ : fraksi berat komponen/senyawa yang masuk 
c. Menghitung Sg dan $\mu$ bahan

$S g$ bahan $=\frac{\rho \text { bahan }}{\rho \text { reference }} x S g$ reference

Keterangan:

$\mathrm{Sg} \quad$ : spesific gravity

$\mathrm{Sg}$ reference : specific gravity dari $\mathrm{H}_{2} \mathrm{O}$

$\mu$ bahan $=\frac{\rho \text { bahan }}{\rho \text { reference }} x \mu$ reference

Keterangan:

$\mu \quad$ : viscositas

d. Rumus Penentuan Harga Alat

Dalam penentuan harga alat, mengikuti tahapan berikut:

i. Menentukan indeks harga alat yang diperoleh dari CEPCI (Chemical Engineering Plant Cost Index) tahun terbaru (CEPCI, 2014)

ii. Menghitung indeks harga dengan metode least square:

$$
\begin{gathered}
\text { Nilai } X \text { : Tahun } \\
\text { Nilai } Y \text { : Indeks harga } \\
X . Y=X^{2} \cdot Y^{2}
\end{gathered}
$$

iii. $\quad$ Rumus dari Peters \& Timmerhause (Pers 21.)

$$
\begin{aligned}
& \sum(\bar{x}-x)^{2}=\sum x^{2}-\frac{\left(\sum x\right)^{2}}{n} \\
& \sum(\bar{y}-y)^{2}=\sum y^{2}-\frac{\left(\sum y\right)^{2}}{n}
\end{aligned}
$$

iv. Rumus dari Peters \& Timmerhause (Pers. 17.20)

$$
\begin{gathered}
\sum(\bar{x}-x)(\bar{y}-y)=\sum x y-\frac{\sum x \sum y}{n} \\
b=\frac{\sum(\bar{x}-x)(\bar{y}-y)}{\sum(\bar{x}-x)^{2}}
\end{gathered}
$$

v. Menentukan rata-rata nilai X dan rata-rata nilai $Y$

vi. Membuat persamaan dari yang sudah dihitung:

Keterangan:

$$
y=a+b(x-c)
$$

a : Nilai rata-rata Y

c : Nilai rata-rata $\mathrm{X}$

$\mathrm{x} \quad$ : Tahun harga alat

\section{HASIL DAN PEMBAHASAN}

Data data yang telah diperoleh kemudian dihitung dan dianalisa. Dari hasil perhitungan, diperoleh:

\section{Over-flow}

Densitas overflow $(\rho \mathrm{B})=52,764 \mathrm{lb} / \mathrm{cuft}$

Densitas overflow $(\rho \mathrm{A})=76,053$

$\mathrm{lb} /$ cuft

Viscositas overflow $=0,0007 \mathrm{lb} / \mathrm{fts}$

\section{Under-flow}

Viscositas underflow $=0,001 \mathrm{lb} / \mathrm{fts}$

\section{Dasar Pemilihan Alat}

L/D = 3 (Ulrich, 1984)

Asumsi:

Decanter terisi $=90 \%$

Pemilihan bahan:

Bahan konstruksi $=$ Carbon Steel SA 283

Grade C (Brownell, 1959)

$\mathrm{F}=12650 \mathrm{psi}$

$\mathrm{E}=0.8$

$\mathrm{C}=0,125$ in

Menghitung Dimensi Tangki Residence:

$$
\text { time }=\frac{6,25 x \mu}{\rho \mathrm{A}-\rho \mathrm{B}}
$$

Keterangan:

$\rho=$ Densitas

$\mu=$ Viskositas

Residence time $=$ waktu tinggal (jam, menit)

\section{Cycle operasi}

Waktu pengisian $=45$ menit

Waktu tinggal $\quad=90$ menit

Waktu pengosongan $=45$ menit

TOTAL

$=3 \mathrm{jam}$

$\rho$ campuran 
Rate Volumetrik:

$$
\begin{gathered}
=\frac{\text { Total Berat Senyawa dalam Bahan }}{\rho \text { campuran bahan }} \\
=\frac{11827,22}{54,445}=217,2 \text { cuft }
\end{gathered}
$$

Volume Decanter:

$$
\begin{aligned}
& =\frac{\text { Rate Volumetrik }}{90 \%} \\
& =\frac{217,2}{90 \%}=241,36 \mathrm{cuft}
\end{aligned}
$$

Volume Decanter (Perry, 1973):

$$
\begin{gathered}
\text { Volume }=\frac{1}{4} \times \Pi \times D^{2} \times L(L=3 D) \\
241,36 \text { cuft }=\frac{1}{4} \times \Pi \times D^{2} \times 3 D
\end{gathered}
$$

Sehingga, diperoleh:

$$
\begin{aligned}
& D=4,67 \mathrm{ft}=56,15 \mathrm{in} \\
& L=14,039 \mathrm{ft}=168,45 \mathrm{in}
\end{aligned}
$$

Penentuan tebal shell dan head decanter:

$\mathrm{H}$ : Tinggi liquid dari dasar tangki $(\mathrm{H}=$ $90 \%$ D)

$\mathrm{H}=4.21 \mathrm{ft}$

P Hidrostatik shell

$P$ hidrostatik shell $=\frac{\rho \mathrm{xZt}}{144}$

$P$ hidrostatik shell $=\frac{54,446 \times 4,211}{144}$

$$
=1,59 P s i
$$

Keterangan:

$\mathrm{Zt}=$ tinggi liquid dari dasar tangki

P Operasi

$$
\text { P.operasi } 14,7+1,59=16,29 P s i
$$

Untuk faktor keamanan $=10 \%$ dari $\mathrm{P}$

Sehingga,

$$
\text { operasi }
$$

$$
\begin{aligned}
\text { P Design } & =1,1 \times \text { P operasi } \\
& =17,921 \mathrm{psi}
\end{aligned}
$$

Berdasarkan Brownell \& Young pers. 13.1, tebal shell diperoleh:

$$
t s=\frac{P x R t}{f . e-0,6 P}+c
$$

Sehingga ditetapkan tebal shell standart $=$ $1 / 6$ in
Tebal Tutup atas

Dari pers. 13.10, Brownell \& Young diperoleh:

$$
t h=\frac{P x R t x W}{2 f \cdot e-0,6 P}+c
$$

th $=0,209 \mathrm{in}$

Dimana, $\mathrm{W}=1.7$ (Brownel, 1959)

$\mathrm{t}=$ tebal shell/tutup

$\mathrm{p}=$ tekanan design

e =efisiensi sambungan las (table 13.2 Brownell\&Young)

$\mathrm{f}=$ stress maksimum yang diijinkan

$\mathrm{r}=$ jari-jari $(\mathrm{D} / 2)$

Ditetapkan tebal tutup atas $=1 / 5$ in

\section{Spesifikasi Alat Decanter}

Kapasitas $=5364.79 \mathrm{~kg} / \mathrm{jam}=5.3 \mathrm{Ton} / \mathrm{jam}$ Tipe = Tangki Silinder Horizontal dengan tutup atas berbentuk dishead

Volume $\quad=241.36 \mathrm{cuft}$

Diameter $\quad=4.68 \mathrm{ft}=1.42 \mathrm{~m}$

Panjang $\quad=14.03 \mathrm{ft}=4.27 \mathrm{~m}$

Tebal shell $\quad=1 / 6$ in

Tebal tutup atas $\quad=1 / 5 \mathrm{in}$

Bahan konstruksi $=$ Carbon steel SA-283 grade $\mathrm{C}$

Jumlah = 1 buah

\section{Perhitungan Spesifikasi Alat}

Ditentukan :

Kapasitas $1 \quad: 10.000$ Ton/tahun

Kapasitas 2 : 20.000 Ton/tahun

Kapasitas 3 : 30.000 Ton/tahun (Pabrik Saya)

Kapasitas $4 \quad$ : 40.000 Ton/tahun 
Erwan Adi Saputro, AR Yelvia dkk. Analisa Teknis dan Ekonomis pada Desain Alat Decanter pada Pabrik Biodiesel

Tabel 1. Perhitungan Spesifikasi Alat

\begin{tabular}{|c|c|c|c|c|c|}
\hline $\begin{array}{c}\text { Spesifi } \\
\text { kasi }\end{array}$ & $\begin{array}{c}\text { Kapasit } \\
\text { as } 1 \\
10.000 \\
\text { ton/ta } \\
\text { hun }\end{array}$ & $\begin{array}{c}\text { Kapasit } \\
\text { as } 2 \\
20.000 \\
\text { ton/ta } \\
\text { hun }\end{array}$ & $\begin{array}{c}\text { Kapasi } \\
\text { tas } 3 \\
30.000 \\
\text { ton/ta } \\
\text { hun }\end{array}$ & $\begin{array}{c}\text { Kapasi } \\
\text { tas } 4 \\
40.000 \\
\text { ton/ta } \\
\text { hun }\end{array}$ & $\begin{array}{c}\text { Keteran } \\
\text { gan }\end{array}$ \\
\hline $\begin{array}{c}\text { Rate } \\
\text { masuk }\end{array}$ & $\begin{array}{c}1788,2 \\
650\end{array}$ & $\begin{array}{c}3576,5 \\
301\end{array}$ & 5364,8 & $\begin{array}{c}7153,0 \\
6\end{array}$ & $\mathrm{Kg} / \mathrm{jam}$ \\
\hline $\begin{array}{c}\text { Volum } \\
\text { e }\end{array}$ & 80,455 & $\begin{array}{c}160,91 \\
1\end{array}$ & $\begin{array}{c}241,36 \\
6\end{array}$ & $\begin{array}{c}321,82 \\
1\end{array}$ & cuft \\
\hline $\begin{array}{c}\text { Diamet } \\
\text { er }\end{array}$ & 3,24 & 4,088 & 4,68 & 5,151 & $\mathrm{ft}$ \\
\hline $\begin{array}{c}\text { Panjan } \\
\mathrm{g}\end{array}$ & 9,734 & 12,265 & 14,039 & 15,452 & $\mathrm{ft}$ \\
\hline $\begin{array}{l}\text { Tebal } \\
\text { shell }\end{array}$ & $1 / 6$ & $1 / 6$ & $1 / 6$ & $1 / 6$ & in \\
\hline $\begin{array}{l}\text { Tebal } \\
\text { tutup } \\
\text { atas }\end{array}$ & $1 / 5$ & $1 / 5$ & $1 / 5$ & $1 / 5$ & in \\
\hline $\begin{array}{c}\text { Bahan } \\
\text { konstr } \\
\text { uksi }\end{array}$ & $\begin{array}{c}\text { Carbon } \\
\text { steel } \\
\text { SA-283 } \\
\text { grade C }\end{array}$ & $\begin{array}{c}\text { Carbon } \\
\text { steel } \\
\text { SA-283 } \\
\text { grade C }\end{array}$ & $\begin{array}{c}\text { Carbon } \\
\text { steel } \\
\text { SA-283 } \\
\text { grade } \\
\text { C }\end{array}$ & $\begin{array}{c}\text { Carbon } \\
\text { steel } \\
\text { SA-283 } \\
\text { grade } \\
\text { C }\end{array}$ & - \\
\hline
\end{tabular}

\section{Perhitungan Harga Alat}

Contoh perhitungan:

Decanter kapasitas 30.000 ton/tahun

Harga pada tahun $2014=\$ .7 .700$

Indeks harga tahun $2014=1590.5$

Indeks harga $2021=1785.2761$

Maka Harga Pada tahun $2021=$

Indeks harga tahun $2021 \quad x$ harga alat tahun 2014

Indeks harga tahun 2014

$=1785.2761 \times \$ .7 .700$

1590.5

$$
=\$ .8 .642
$$

Untuk kapasitas yang lain dapat dilihat pada tabel 2.
Tabel 2. Perhitungan Spesifikasi Alat

\begin{tabular}{|c|c|c|c|c|c|}
\hline $\begin{array}{c}\text { Spesifi } \\
\text { kasi }\end{array}$ & $\begin{array}{c}\text { Kapasit } \\
\text { as } 1 \\
10.000 \\
\text { ton/tah } \\
\text { un }\end{array}$ & $\begin{array}{c}\text { Kapasit } \\
\text { as } 2 \\
20.000 \\
\text { ton/tah } \\
\text { un }\end{array}$ & $\begin{array}{c}\text { Kapasit } \\
\text { as } 3 \\
30.000 \\
\text { ton/tah } \\
\text { un }\end{array}$ & $\begin{array}{c}\text { Kapasit } \\
\text { as } 4 \\
40.000 \\
\text { ton/tah } \\
\text { un }\end{array}$ & $\begin{array}{c}\text { Ketera } \\
\text { ngan }\end{array}$ \\
\hline $\begin{array}{c}\text { Rate } \\
\text { masuk }\end{array}$ & $\begin{array}{c}1788,2 \\
650\end{array}$ & $\begin{array}{c}3576,5 \\
301\end{array}$ & 5364,8 & $\begin{array}{c}7153,0 \\
6\end{array}$ & $\begin{array}{c}\mathrm{Kg} / \mathrm{ja} \\
\mathrm{m}\end{array}$ \\
\hline $\begin{array}{l}\text { Diame } \\
\text { ter } \\
\text { tangki }\end{array}$ & 3,24 & 4,088 & 4,68 & 5,151 & $\mathrm{Ft}$ \\
\hline $\begin{array}{c}\text { Harga } \\
\text { perkir } \\
\text { aan } \\
\text { (US \$) }\end{array}$ & 6.986 & 7.442 & 8.642 & 10.177 & - \\
\hline $\begin{array}{l}\text { Harga } \\
\text { perkir } \\
\text { aan } \\
\text { (Rp) }\end{array}$ & $\begin{array}{c}101.50 \\
6.580\end{array}$ & $\begin{array}{c}108.13 \\
2.260\end{array}$ & $\begin{array}{c}125.58 \\
2.192\end{array}$ & $\begin{array}{c}147.00 \\
0.010\end{array}$ & $\begin{array}{c}1 \text { US.\$ } \\
=\text { Rp. } 14 \\
.500\end{array}$ \\
\hline
\end{tabular}

Pada Tabel 2 menunjukkan bahwa dengan perhitungan 4 kapasitas yang berbeda menunjukkan kenaikan harga perkiraan seiring bertambahnya jumlah kapasitas yang diberikan seperti dari kapasitas 1 (10.000 ton/tahun) dengan spesifikasi decanter berdiameter 3,24 ft dan perkiraan harganya Rp. 101.506.580. Kapasitas 2 (20.000 ton/tahun) dengan spesifik alat berdiameter 4,088 ft serta perkiraan harganya Rp. 108.132.260. Lalu dengan kapasitas 3 (30.000 ton/tahun) memerlukan spesifikasi berdiameter $4,68 \mathrm{ft}$ dengan perkiraan harga Rp. 125.582.192 . Kemudian dengan kapasitas 4 (40.000 ton/tahun) memerlukan spesifikasi dengan diameter decanter 5,151 ft dengan perkiraan harga Rp. 147.000.010. 
Hubungan Kapasitas dengan Harga Alat Decanter

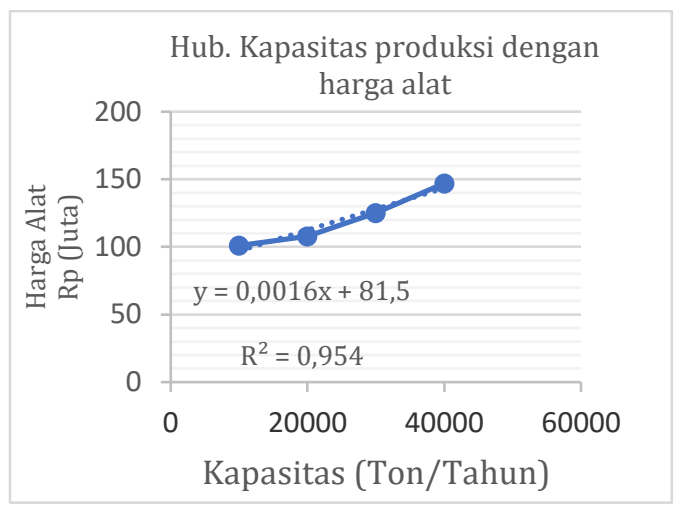

Gambar 2 Hubungan Kapasitas dengan Harga Alat

Berdasarkan gambar 2, dapat dijelaskan bahwa dengan perhitungan 4 kapasitas yang berbeda menunjukkan kenaikan harga alat seiring bertambahnya jumlah kapasitas yang diberikan seperti dari kapasitas 1 (10.000 ton/tahun) dengan spesifikasi decanter berdiameter 3,24 ft dan perkiraan harganya Rp. 101.506.580. Kapasitas 2 (20.000 ton/tahun) dengan spesifik alat berdiameter 4,088 ft serta perkiraan harganya Rp. 108.132.260. Lalu dengan kapasitas 3 (30.000 ton/tahun) memerlukan spesifikasi berdiameter $4,68 \mathrm{ft}$ dengan perkiraan harga Rp. 125.582.192. Kemudian dengan kapasitas 4 (40.000 ton/tahun) memerlukan spesifikasi dengan diameter decanter 5,151 ft dengan perkiraan harga Rp. 147.000.010. Pada grafik yang disajikan dapat disimpulkan bahwa kenaikan harga alat berlinear dengan seiring bertambahnya jumlah kapasitas karena feed yang masuk ke dalam alat decanter semakin besar sehingga biaya pembuatan alat decanter semakin mahal

\section{Perbandingan Harga Alat Decanter}

Tabel 3. Harga decanter dipasaran (Alibaba, 2019)

\begin{tabular}{|l|l|l|l|}
\hline $\begin{array}{l}\text { Spesifika } \\
\text { si }\end{array}$ & $\begin{array}{l}\text { Wuxi } \\
\text { Dajiang } \\
\text { Enviroment } \\
\text { al } \\
\text { Technology } \\
\text { Co, LTD }\end{array}$ & $\begin{array}{l}\text { Sino } \\
\text { Pharmaceutic } \\
\text { al Equipment } \\
\text { (Liaoyang) Co } \\
\text { LTD }\end{array}$ & $\begin{array}{c}\text { Keteranga } \\
n\end{array}$ \\
& $\begin{array}{l}4.000- \\
\text { kapasitas }\end{array}$ & $\begin{array}{l}20.000- \\
100.000\end{array}$ & $\begin{array}{l}\text { Ton/Tahu } \\
\text { n }\end{array}$ \\
\hline $\begin{array}{l}\text { Harga } \\
\text { (Rp) }\end{array}$ & $\begin{array}{l}72.118 .000- \\
468.620 .00\end{array}$ & $\begin{array}{l}98.590 .000- \\
611.540 .000\end{array}$ & $\begin{array}{l}\text { 1US.\$ } \\
=\text { Rp.14.50 } \\
0\end{array}$ \\
\hline
\end{tabular}

Berdasarkan tabel 3 di atas, menunjukkan bahwa semakin besar kapasitas decanter maka harganya akan semakin tinggi dikarenakan feed yang masuk juga semakin banyak sehingga diameter tangki decanter semakin besar.

\section{KESIMPULAN}

Berdasarkan estimasi perhitungan harga Decanter, dapat disimpulkan bahwa semakin besar kapasitas Decanter maka semakin tinggi harganya karena jumlah feed yang masuk ke alat mempengaruhi ukuran dimensi alat tersebut. Hasil dari perhitungan dengan kapasitas 3 (30.000 ton/tahun) dengan diameter 4,68 ft diperkiraan harganya Rp. 125.582.192, kemudian harga beli alat Decanter dipasaran dengan kapasitas 25.000 ton/tahun adalah Rp. 110.680.000- . Sehingga dapat disimpulkan bahwa metode perhitungan ini memadai dan sesuai dengan harga pasaran.

\section{DAFTAR PUSTAKA}

Alibaba. 2019. Decanter. Diunduh di https://www.alibaba.com/showroom/dec anter-centrifuge-price.html.

Brownell, A. 2017. Pemanfaatan Basculator Dalam Operasioanl Decanter Untuk Menghitung 
Erwan Adi Saputro, AR Yelvia dkk. Analisa Teknis dan Ekonomis pada Desain Alat Decanter pada Pabrik Biodiesel

Tonase Oil. Jurnal Citra Widya Edukasi, 9(2)m125-129.

Brownell, L. 1959. "Process Equipment Design (Vessel Design)". Wiley:University of Michigan.

Budiman, A. 2009. Metode Sentrifugasi untuk Pemisahan Biodiesel dalam Proses Pencucian. Jurnal Riset Industri, 3(3), 173178.

Cepci. 2014. Economic Indicator. www.Chemengonline.com.

Palm Oil Industrial Engineering. 2013.“Decanter (equipment sludge treatment) surgapetani.blogspot.com/2013/01/decan ter-equiment-sludge-treatment.html.

Diakses pada tanggal 16 April 2021 pukul 08.20 WIB.

Perry, Robert H. 1973. "Perry's Chemical Engineer's
Handbook" , 5th edition. New York : McGraw-Hill Book Company Inc.

Peter And Timmerhaus. 1991. Plant Design And Economic For Chemical Engineering. Newyork. Mc Graw Hill.

Soerawidjaja, Tatang H. 2005. "Minyak Lemak dan Produk-Produk Kimia lain dari Kelapa". Handout Kuliah Proses Industri Kimia, Program Studi Teknik Kimia, Institut Teknologi Bandung.

Ulrich, G. 1984. "A Guide To Chemical Engineering Process Design and Economics". Willey: University of Newhampsire.

Zhu, M., Hu, D., Xu, Y., dan Zhao, S. 2020. “Design and Computational Fluid Dynamics Analysis of a Three-Phase Decanter Centrifuge for OilWater-Solid Separation". Chem. Eng. Technol. 43, 1005-101. 